\title{
Some Considerations on the Atmospheric Internal Boundary Layer over the Ground Surface
}

\author{
by \\ Shigeru Nemoto \\ Meteorological Research Institute, Tokyo \\ (Received December 17, 1971)
}

\begin{abstract}
According to BRADLEY, velocity changes do not agree fairly well with the PANOFSKY and TownsEND theory in the rough-smooth direction. This problem is reexamined by the use of BRADLEY's data. It is concluded that the velocity profiles observed agree fairly well with those predicted by the PANOFSKY and TOWNSEND theory also in this case by a reasonable choice of roughness parameters.
\end{abstract}

\section{Introduction}

Experimental studies of the roughness transition in the atmosphere have been performed by KutzBaCH (1961), STEARNS (1964), Stearns and LeTTAU (1963) and BRADLEY (1968). On the other hand, three theoretical approaches to the problem have come from ELLIOTT (1958), TAYLOR (1962) and PANOFSKY and TOWNSEND (1963).

According to BRADLEY, the theoretically predicted velocity profiles downwind of rough-smooth transition were found to have smaller values than those actually observed, as the fetch over the smooth surface increased. That is, the flow got acceleration over the predicted values. BRADLEY has not discussed the mechanism of the acceleration. Is acceleration in this sense really present? We examined this problem by the use of BRADLEY's data, which were obtained under neutral or near neutral conditions.

\section{Models of the atmospheric internal boundary layer}

A schematic diagram of the internal boundary layer is shown in Fig. 1. The transition (from rough to smooth in this case) takes place at A. The internal boundary layer (region 2) develops downwind of A. The familiar logarithmic velocity profile given by

$$
\frac{U}{v_{* 1}}=\frac{1}{\kappa} \ln \frac{z}{z_{01}}
$$




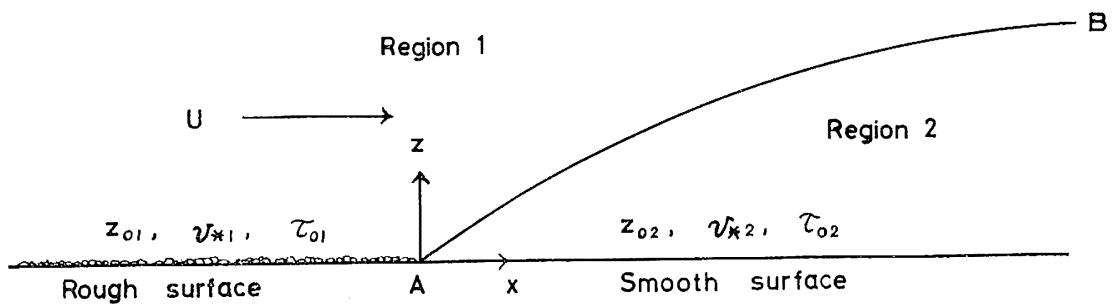

Fig. 1. Schematic representation of the transition region.

is supposed to hold upwind of $\mathrm{A}$, and outside the boundary layer interface $\mathrm{AB}$ (ELLIOTT, PANOFSKY and TOWNSEND, TAYLOR), and this unmodified part of the surface boundary layer is called region 1 in this paper, where

$u$ : mean horizontal velocity at a height of $z$,

$v_{* 1}$ : friction velocity,

$z_{01}$ : roughness parameter,

$\kappa$ : von Karman's constant.

The following two velocity profiles have bcen proposed in region 2 .

1) The velocity profile

$$
\frac{u}{v_{* 2}}=\frac{1}{\kappa} \ln \frac{z}{z_{02}}
$$

is proposed by ELLIOTT, where

$u$ : mean horizontal velocity at a height of $z$,

$v_{* 2}:$ friction velocity,

$z_{02}$ : roughness parameter.

In this model, velocity is continuous but stress is not at the interface $A B$.

2) The velocity profile

$$
\frac{u}{v_{* 1}}=\frac{1}{\kappa}\left[(1-S) \ln \frac{z}{z_{02}}+S \frac{z}{\delta^{\prime}}\right]
$$

is proposed by PANOFSKY and TOWNSEND and this is derived from the relation

$$
\frac{\partial u}{\partial z}=\frac{v_{*}}{\kappa z}
$$

which holds for the equilibrium flow, on the assumption that

$$
v_{*}=v_{* 1}\left[(1-S)+S \frac{z}{\delta^{\prime}}\right]
$$

where

$$
S=\frac{v_{* 1}-v_{* 2}}{v_{* 1}}
$$

$\delta^{\prime}$ : height of the modified region defined by the PANOFSKY and TownSEND theory (PANOFSKY-TOWNSEND interface height).

In this case, friction velocity varies linearly with height and is continuous at the 
interface $A B$.

TAYLOR has proposed the velocity profile

$$
\frac{u}{v_{* 2}}=\frac{1}{\kappa} \ln \frac{z}{z_{02}}
$$

for the region far leeward of the transition, but this case will not be treated here.

\section{Height of the modified region}

The height of the modified region is a function of fetch over the smooth surface, $x$. The interface height defined by the ELLIOTT theory $\delta$ and that defined by the PANOFSKY and TOWNSEND theory $\delta^{\prime}$ will be estimated as follows:

1) ElLIOTT interface height $\delta$

ELLIOTT supposed the velocity profile (2.1) for region 1 and (2.2) for region 2. Therefore, if $U=u=u_{\delta}$ at $z=\delta$, at a certain fetch, and $u_{\delta}$ is eliminated by using equations (2.1) and (2.2), the relation

$$
\frac{v_{* 2}}{v_{* 1}}=\frac{\ln \delta-\ln z_{01}}{\ln \delta-\ln z_{02}}
$$

may be obtained. Then, the relation

$$
\log \delta=\frac{\log z_{01}-R \log z_{02}}{1-R}
$$

can be derived by the substitution of $R$ for $v_{* 2} / v_{* 1}$. Therefore, $\delta$ is finally given as

$$
\delta=\left(\frac{z_{01}}{z_{02}^{R}}\right)^{\frac{1}{1-R}}
$$

It will be seen from the above relation that $\delta$ is the function of $z_{01}, z_{02}, v_{* 1}$ and $v_{* 2}$.

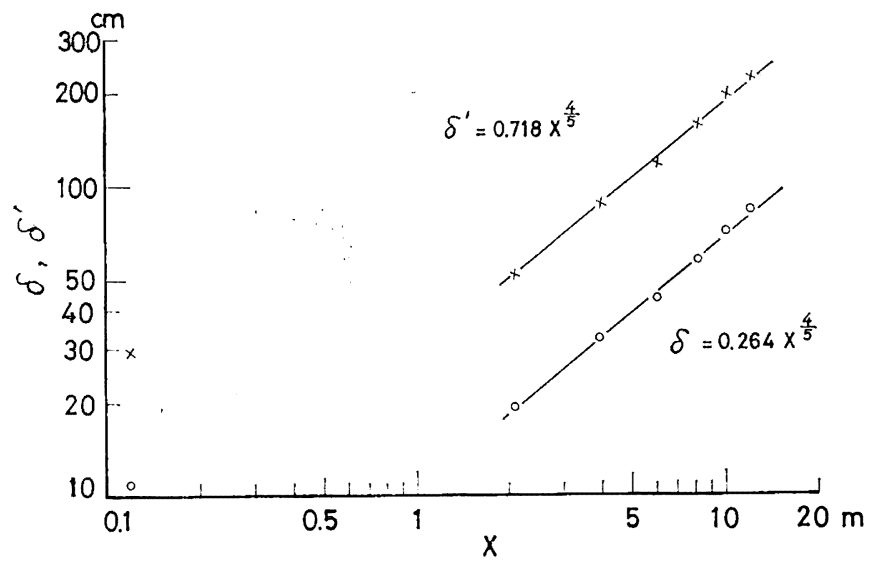

Fig. 2. Height of the modified region downwind of rough-smooth (spikes-tarmac) transition. 
The lower curve in Fig. 2 shows the relation between $x$ and $\delta$ calculated by equation (3.1) using $z_{01}, z_{02}, v_{* 1}$ and $v_{*^{2}}$ at each fetch, which are obtained from the set of velocity profiles observed by BRADLEY. It will be seen from the figure that the relation

$$
\delta=a x^{\frac{4}{5}}
$$

holds for $x$ more than $4.0 \mathrm{~m}$. The experimental constant $a$ may be determined by the figure as

$$
a=0.264
$$

Therefore, the empirical formula (3.3) can be written as

$$
\delta=0.264 x^{\frac{4}{5}} \quad(\mathrm{~cm})
$$

The experimental constant $a$ is not a universal one and depends on roughness. The set of observations in the case of the spikes-tarmac transition were used here.

2) PANOFSKY-TOWNSEND interface height $\delta^{\prime}$.

PANOFSKY and TOWNSEND supposed the velocity profile (2.1) for region 1 and (2.3) for region 2. Then, if $U=u=u_{\delta^{\prime}}$ at $z=\delta^{\prime}$, at a certain fetch, the relation

$$
\ln \delta^{\prime}=\frac{\ln z_{01}-R \ln z_{02}+(1-R)}{1-R}
$$

may be obtained from equations (2.1) and (2.3) in the same way as mentioned above. The relation (3.5) can also be written as

$$
\delta^{\prime}=e\left(\frac{z_{01}}{z_{02}^{R}}\right)^{\frac{1}{1-R}}
$$

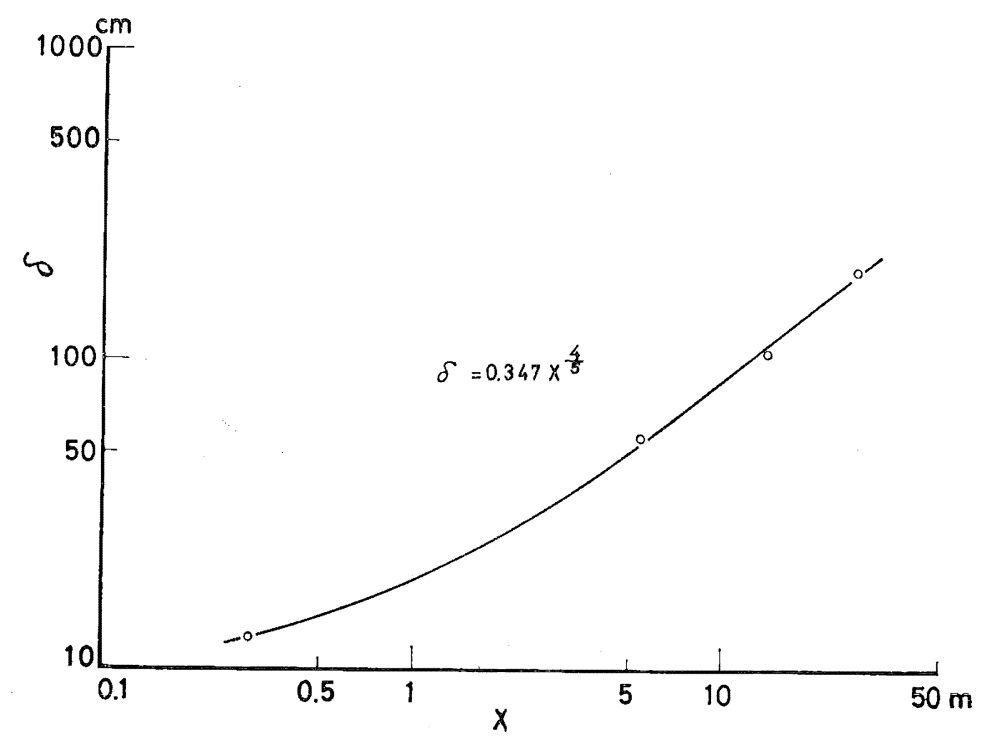

Fig. 3. Height of the modified region downwind of rough-smooth (grass-tarmac) transition. 
Therefore, it will be seen from a comparison of the above relation with (3.2) that the PANOFSKY-TOWNSEND interface height $\delta^{\prime}$ is $e(=2.72)$ times the ElLIOTT interface height $\delta$. The upper curve in Fig. 2 shows the relation between $\delta^{\prime}$ and $x$. The linear part of this curve may be represented by

$$
\delta^{\prime}=0.718 x^{\frac{4}{5}} \quad(\mathrm{~cm})
$$

Another of BRADLEY's observations concerns the grass-tarmac transition. The relation between $\delta$ and $x$ in this case is shown in Fig. 3. The linear part of the curve is represented by

$$
\delta=0.347 x^{\frac{4}{5}}
$$

The PANOFSKY-TOWNSEND interface height $\delta^{\prime}$ is also $e$ times the above-mentioned $\delta$.

Since the velocity profile at each fetch downwind of the transition is not observed simultaneously, each velocity profile in region 1 corresponding to each observation run is usually different, so that $z_{01}, z_{02}, v_{* 1}$ and $v_{*^{2}}$ in each run are also different as shown in Table 1 to be given later. But it is interesting to note that there is, nevertheless, a definite relation between $\delta$ and $x$.

\section{Variation of surface shearing stress downwind of rough-smooth transition}

If the shearing stresses on the surfaces of region 1 and region 2 are represented by $\tau_{01}$ and $\tau_{02}$, respectively, since

$$
\tau_{01}=\rho v_{* 1}^{2}, \quad \tau_{02}=\rho v_{* 2}^{2}
$$

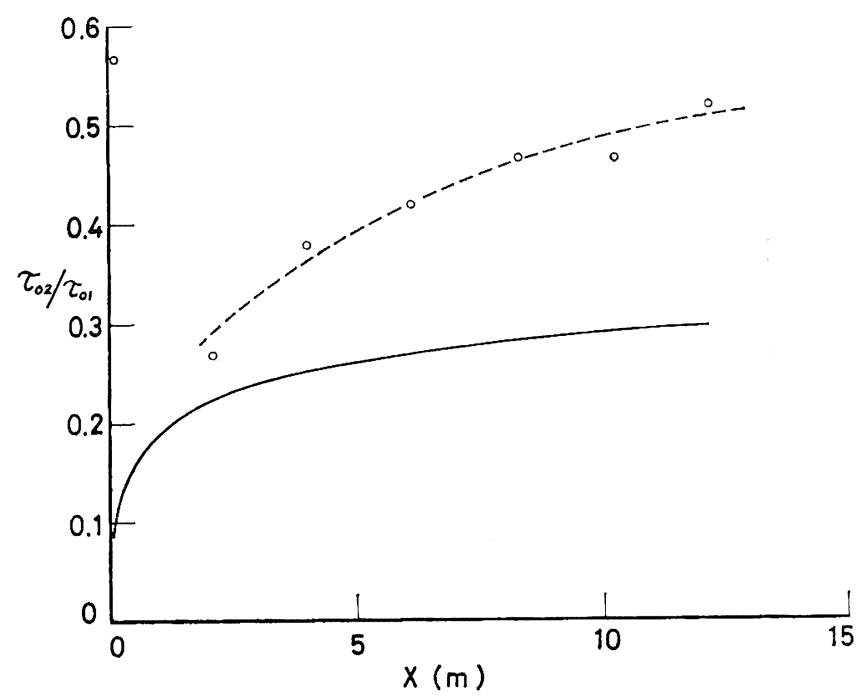

Fig. 4. Variation of surface shearing stress downwind of rough-smooth (spikes-tarmac) transition. 
then

$$
\frac{\tau_{02}}{\tau_{01}}=\left(\frac{v_{* 2}}{v_{* 1}}\right)^{2}=R^{2}=\left(\frac{\log \delta-\log z_{01}}{\log \delta-\log z_{02}}\right)^{2}
$$

As seen from the above relation, $\tau_{02} / \tau_{01}$ is the function of $z_{01}, z_{02}$ and $\delta$ or 2 . When $z_{01}, z_{02}$ and $\delta$ at each $x$ are given $\tau_{02} / \tau_{01}$ at each $x$ may be estimated by the relation (4.1).

BRADLEY gave $z_{01}=0.25 \mathrm{~cm}, z_{02}=0.002 \mathrm{~cm}$ for the spikes-tarmac transition. When we calculate $\tau_{02} / \tau_{01}$ at each fetch $x$ using these values of $z_{01}$ and $z_{02}$ and further $\delta$ obtained from the empirical formula (3.4), we obtain the curve shown by the solid line in Fig. 4. On the other hand, $\tau_{02} / \tau_{01}$ at each fetch $x$ estimated by using $v_{* 1}$ and $v_{*^{2}}$ obtained from the observed velocity profiles is shown by the broken line in the figure. There is considerable difference between the two curves. It seems that this is due to differences in $z_{01}$ and $z_{02}$ between the two cases. Values of $z_{01}$ estimated by the observed velocity profiles range from $0.14 \mathrm{~cm}$ to $0.008 \mathrm{~cm}$, and those of $z_{02}$ range from $0.0015 \mathrm{~cm}$ to $0.00023 \mathrm{~cm}$ (Table 1, shown later). These values differ considerably from those chosen by BRADLEY, who estimates them by the extreme velocity profiles above both surfaces (rough and smooth), which are considered to be typical. The value of $z_{02} / z_{01}$ determined by the observed velocity profiles is 0.029 on the average and that chosen by BRADLEY is 0.008 .

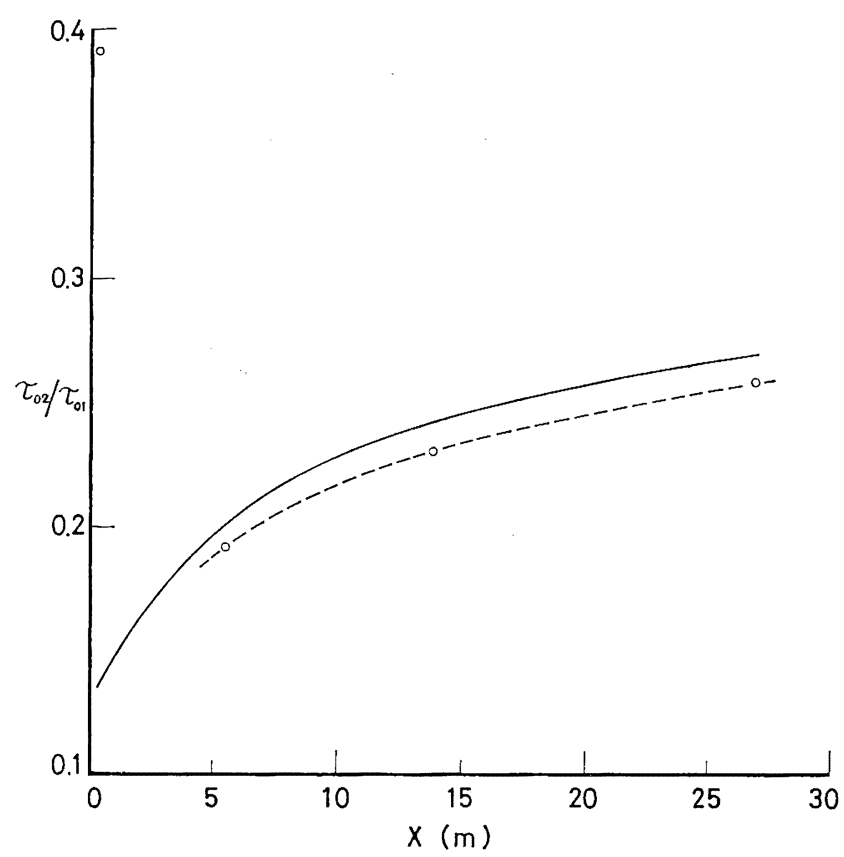

Fig. 5. Variation of surface shearing stress downwind of rough-smooth (grasstarmac) transition. 
Another of BRADLEY's observations, which concerns the grass-tarmac transition, is shown in Fig. 5. In this case BRADLEY choses $z_{01}=0.5 \mathrm{~cm}$ and $z_{02}=0.002 \mathrm{~cm}$, but on the other hand $z_{01}=0.5 \mathrm{~cm}$ and $z_{02}=0.0015 \mathrm{~cm}$ are estimated by the set of velocity profiles observed. Since the values of $z_{01}$ and $z_{02}$ of the two cases are not widely different, the two curves are comparatively close to each other. But eventually it will be found from these results that $\tau_{02} / \tau_{01}$ is sensitive to the change of roughness parameters.

\section{Comparison of the observed velocity profiles with those predicted by the PANOFSKY and TOWNSEND theory}

According to BRADLEY, the velocity profiles predicted by the PANOFSKY and TOWNSEND theory coincide well with the observed ones for shorter fetches, but turn out to have smaller values than the observed ones for longer fetches, that is, the observed velocity profiles seem to be accelerated (cf. BRADLEY's paper, Figs. 9 and 10). He did not discuss the reason for this acceleration, whose mechanism seems difficult to explain.

According to the PANOFSKy and Townsend theory, as described above, the velocity profile in region 2 may be represented by

$$
\frac{u}{v_{* 2}}=\frac{1}{\kappa}\left[(1-S) \ln \frac{z}{z_{02}}+S \frac{z}{\delta^{\prime}}\right]
$$

This equation is written as

$$
\frac{v_{k}}{v_{* 2}}=\frac{1}{\kappa} \ln \frac{z}{z_{02}}+\frac{1}{\kappa}\left(\frac{1}{R}-1\right) \frac{z}{\delta^{\prime}}
$$

by the substitution of $R$ for $v_{* 2} / v_{* 1}$, In this equation, the first term of the righthand side represents the velocity profile of the ELLIOTT theory.

Since BRADLEY has adopted the velocity $u_{112.5}$ at $z=112.5 \mathrm{~cm}$ in region 1 as the reference velocity to represent the velocity profiles downwind of the spikes-tarmac transition, we also use the following equation to be derived from equations (2.1) and (5.1), to make comparison easy,

$$
\frac{u}{u_{112.5}}=\frac{R \ln \frac{z}{z_{02}}+(1-R) \frac{z}{\delta^{\prime}}}{\ln \frac{112.5}{z_{01}}}
$$

First, we estimate $z_{01}, v_{* 1}, z_{02}, v_{* 2}, z_{02} / z_{01}, \tau_{02} / \tau_{01}, \delta$ and $\delta^{\prime}$ at each $x$ by the use of the set of velocity profiles observed by BRADLEY. The results are shown in Table 1 . Since BRADLEY observed velocity profiles at $x=0.12,2.1,4.0,6.1,8.3,10.2,12.2 \mathrm{~m}$ by moving the anemometer mast in turn, the velocity profiles at each fetch were generally different, because the natural wind cannot remain steady for long; therefore $z_{01}, z_{02}$, $v_{* 1}$ and $v_{* 2}$ are also different in each run. However, the values of $z_{02} / z_{01}$ take an almost 
constant value $(0.0297$ on the average) for fetches more than $4.1 \mathrm{~m}$, except for shorter fetches.

Table 1. Roughness parameters, friction velocities, ratio of shearing stresses and interface heights estimated by the use of the set of velocity profiles observed by Bradley (spikestarmac transition).

\begin{tabular}{|c|c|c|c|c|c|c|c|c|}
\hline $\begin{array}{l}x \\
\mathrm{~m}\end{array}$ & $\begin{array}{l}z_{01} \\
\mathrm{~cm}\end{array}$ & $\begin{array}{c}v_{* 1} \\
\mathrm{~cm} / \mathrm{s}\end{array}$ & $\begin{array}{l}z_{02} \\
\mathrm{~cm}\end{array}$ & $\begin{array}{c}v_{* 2} \\
\mathrm{~cm} / \mathrm{s}\end{array}$ & $z_{02} / z_{01}$ & $\tau_{02} / \tau_{01}$ & $\begin{array}{c}\delta \\
\mathrm{cm}\end{array}$ & $\begin{array}{r}\delta^{\prime} \\
\mathrm{cm}\end{array}$ \\
\hline 0.12 & 0.18 & 42.0 & 0.047 & 31.6 & 0.261 & 0.565 & 10.9 & 29.6 \\
\hline 2.10 & 0.14 & 38.2 & 0.0015 & 19.8 & 0.011 & 0.269 & 19.1 & 52.0 \\
\hline 4.00 & 0.12 & 42.3 & 0.0035 & 26.0 & 0.0292 & 0.378 & 32.0 & 87.0 \\
\hline 6.10 & 0.075 & 42.0 & 0.0024 & 27.2 & 0.0320 & 0.419 & 42.7 & 116.1 \\
\hline 8.30 & 0.027 & 35.6 & 0.0008 & 24.3 & 0.0296 & 0.467 & 56.2 & 152.9 \\
\hline 10.20 & 0.038 & 40.5 & 0.0011 & 27.6 & 0.0290 & 0.465 & 70.8 & 192.5 \\
\hline 12.20 & 0.008 & 28.1 & 0.00023 & 20.3 & 0.0288 & 0.518 & 83.2 & 226.2 \\
\hline
\end{tabular}

Although BRADLEY predicted the velocity profiles by using $z_{01}=0.25 \mathrm{~cm}$ and $z_{02}=$ $0.002 \mathrm{~cm}$, which were estimated by the extreme velocity profiles in each region (1 and 2), we considered that the wind with a logarithmic profile characterized by $z_{01}$ and $v_{* 1}$ as shown in each run in Table 1 was modified by the spikes-tarmac transition. That is, we predicted the velocity profiles from equation (5.2) by using $z_{02}$ estimated by multiplying $z_{01}$ shown in the table by 0.0297 and $\delta^{\prime}$ at each corresponding $x$. These results are shown by solid lines in Fig. 6-Fig.10. Velocities observed at each height (BRADLEY) are also shown by $\bigcirc$ in the figures. On the other hand, the velocity profiles predicted from equation (5.2) by using $z_{01}$ and $z_{02}$ chosen by BRADLEY are shown by broken lines.

It will be seen from the above figures that there is no significant difference between the velocity profiles predicted by the author and those predicted by BRADLEY for shorter fetches, that is, for 4.0 and $6.1 \mathrm{~m}$, and both velocity profiles also agree well with the observed ones, but the velocity profiles represented by the broken line indicate lower velocity for fetches more than $6.1 \mathrm{~m}$, while the velocity profiles shown by the solid line fit the observed ones. That is, the observed velocity profile seems to show acceleration over the one which was predicted by BRADLEY by using the PANOFSKY-TOWNSEND theory. On the contrary, the velocity profiles predicted by the author well fit the observed ones at each fetch and acceleration can not be found. This is due to difference in the choice of $z_{01}$ and $z_{02}$ between the cases. BRADLEY has determined the values of $z_{01}$ and $z_{02}$ by the use of the extreme velocity profiles in each of regions 1 and 2, but it seems that these values do not always show the actual situation.

The case of grass-tarmac transition will be described in the following as another example. The values of $z_{01}, v_{* 1}, z_{02}, v_{* 2}, z_{02} / z_{01}, \tau_{02} / \tau_{01}, \delta$ and $\delta^{\prime}$ at each fetch over the tarmac surface in this case are shown in Table 2. 


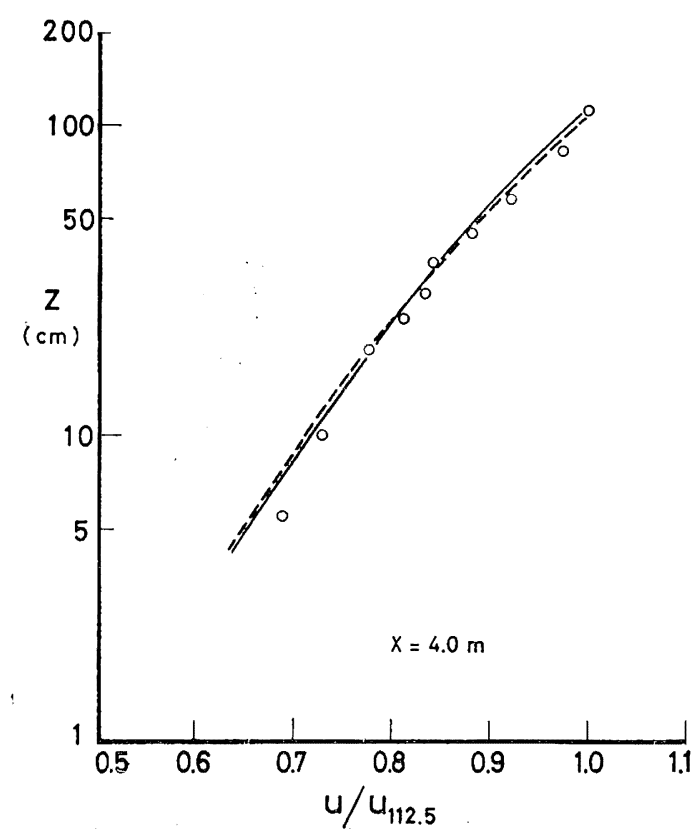

Fig.6. Velocity profile downwind of rough-smooth (spikes-tarmac) transition (fetch over tarmac surface $x=4.0 \mathrm{~m}, \delta=32 \mathrm{~cm}$ ).

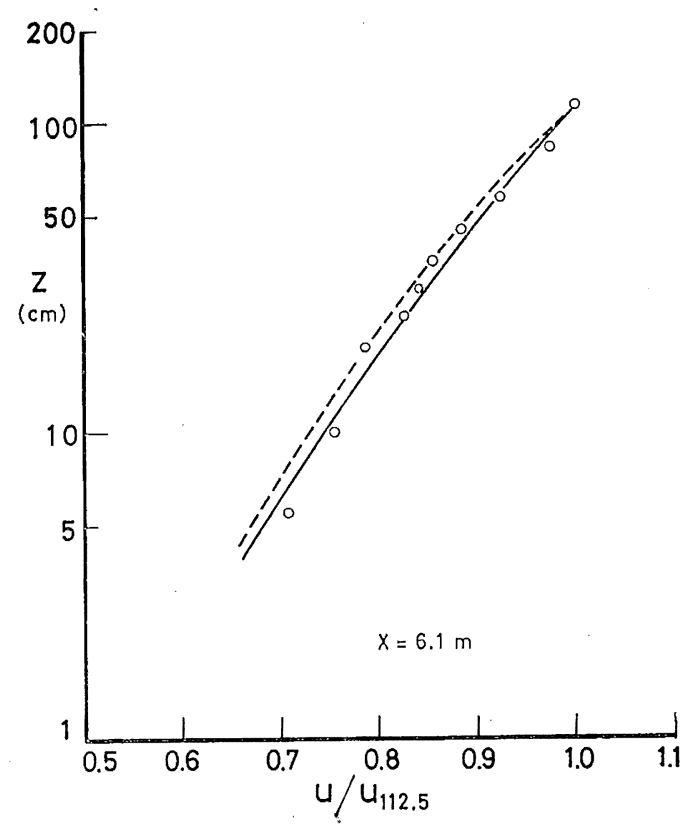

Fig. 7. Velocity profile downwind of rough-smooth (spikes-tarmac) transition $(x=6.1 \mathrm{~m}, \delta=42.7 \mathrm{~cm})$. 


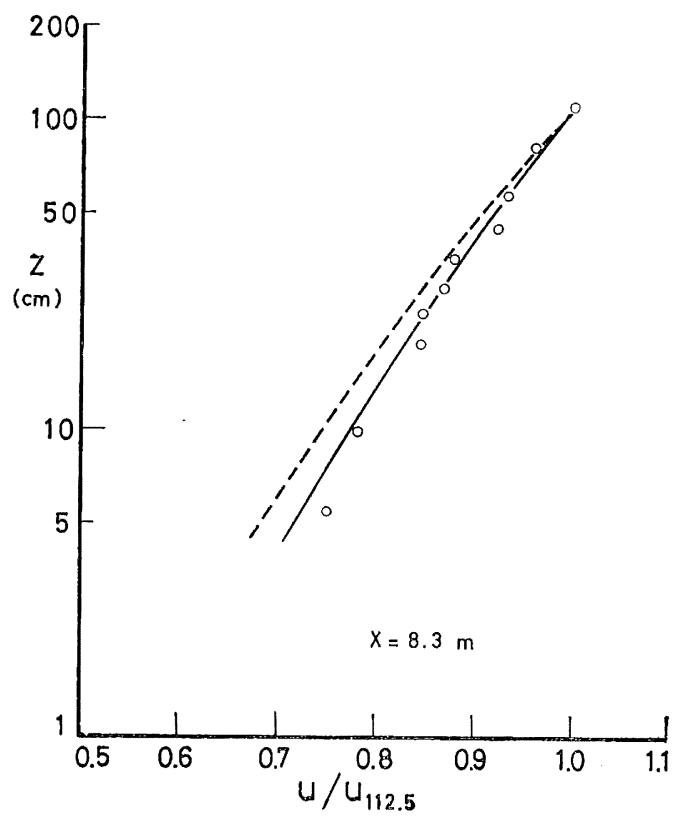

Fig. 8. Velocity profile downwind of rough-smooth (spikes-tarmac) transition $(x=8.3 \mathrm{~m}, \delta=56.2 \mathrm{~cm})$.

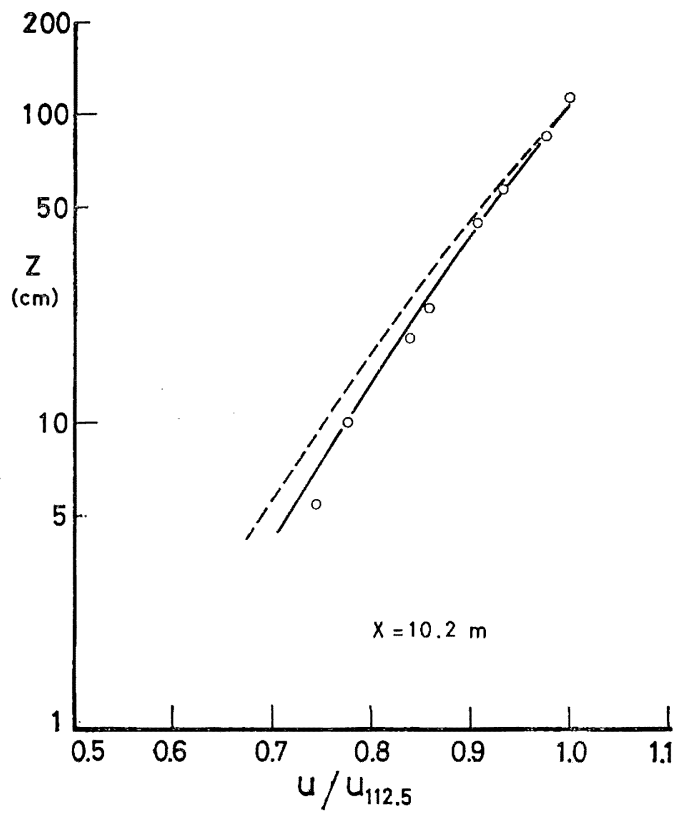

Fig. 9. Velocity profile downwind of rough-smooth (spikes-tarmac) transition $(x=10.2 \mathrm{~m}, \delta=70.8 \mathrm{~cm})$. 


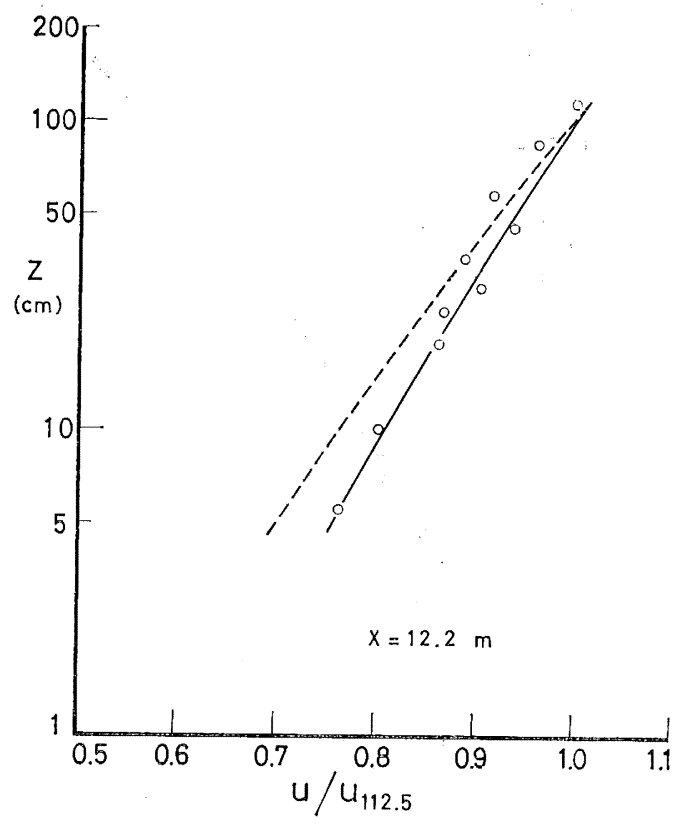

Fig. 10. Velocity profile downwind of rough-smooth (spikes-tarmac) transition $(x=12.2 \mathrm{~m}, \delta=83.2 \mathrm{~cm})$.

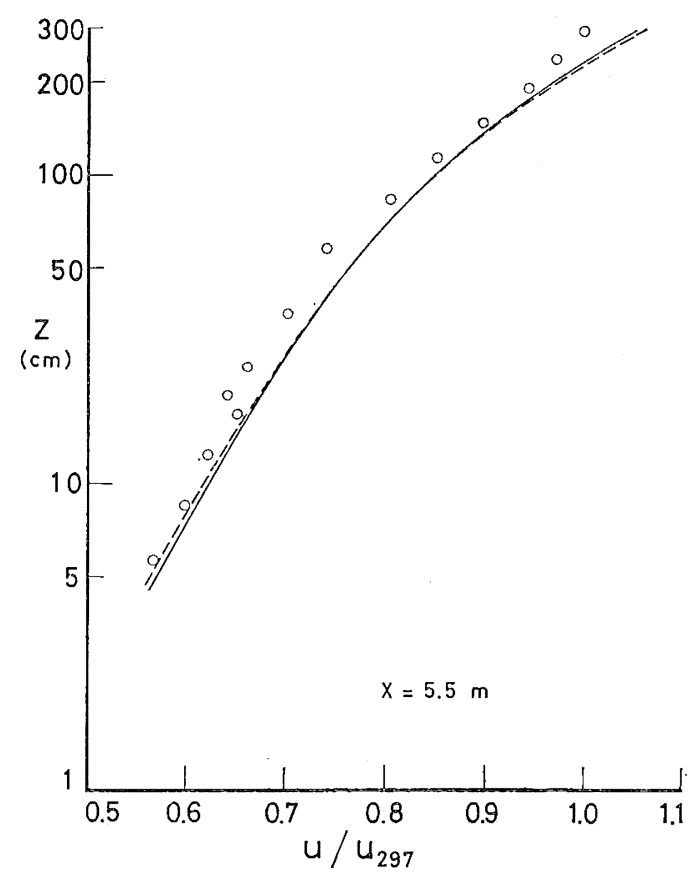

Fig. 11. Velocity profile downwind of rough-smooth (grass-tarmac) transition $(x=5.5 \mathrm{~m}, \delta=46.4 \mathrm{~cm})$. 


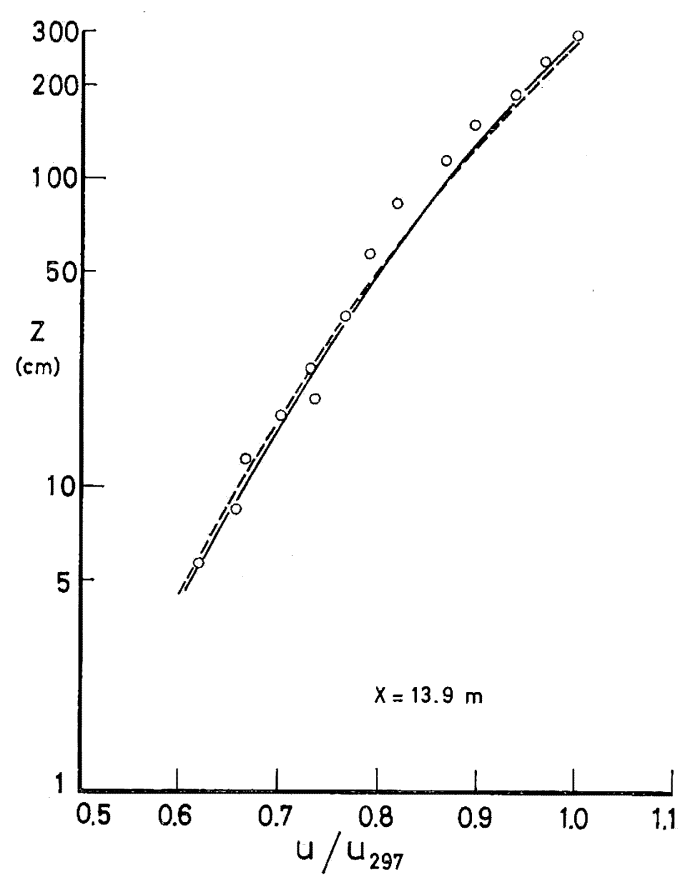

Fig. 12. Velocity profile downwind of rough-smooth (grass-tarmac) transition $(x=13.9 \mathrm{~m}, \delta=106 \mathrm{~cm})$.

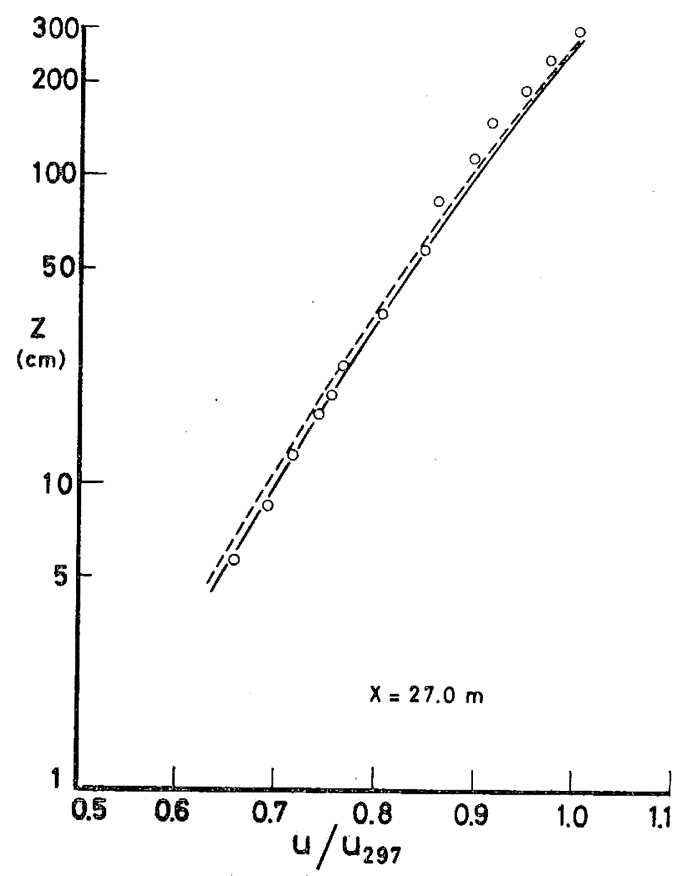

Fig. 13. Velocity profile downwind of rough-smooth (grass-tarmac) transition $(x=27.0 \mathrm{~m}, \delta=199.5 \mathrm{~cm})$. 
Table 2. Roughness parameters, friction velocities, racio of shearing stresses and interface heights estimated by the use of the set of velocity profiles observed by Bradley (grasstarmac transition),

\begin{tabular}{|c|c|c|c|c|c|c|c|c|}
\hline $\begin{array}{l}x \\
\mathrm{~m}\end{array}$ & $\begin{array}{l}z_{01} \\
\mathrm{~cm}\end{array}$ & $\begin{array}{c}v_{* 1} \\
\mathrm{~cm} / z\end{array}$ & $\begin{array}{l}z_{02} \\
\mathrm{~cm}\end{array}$ & $\begin{array}{c}v_{\circledast 2} \\
\mathrm{~cm} / \mathrm{s}\end{array}$ & $z_{02} / z_{01}$ & $\tau_{02} / \tau_{01}$ & $\begin{array}{c}\delta \\
\mathrm{cm}\end{array}$ & $\begin{array}{c}\delta^{\prime} \\
\mathrm{cm}\end{array}$ \\
\hline 0.3 & 0.72 & 17.5 & 0.13 & 11.0 & 0.181 & 0.391 & 12.6 & 34.2 \\
\hline 5.5 & 0.50 & 13.0 & 0.0015 & 5.7 & 0.003 & 0.192 & 46.4 & 126.1 \\
\hline 13.9 & 0,50 & 18.8 & 0.0015 & 9.0 & 0.003 & 0.230 & 106.0 & 288.0 \\
\hline 27.0 & 0.50 & 23.8 & 0.0015 & 12.1 & 0.003 & 0.258 & 199.5 & 543.0 \\
\hline
\end{tabular}

In this case, the values of $z_{02} / z_{01}$ at each $x$ estimated by the observed velocity profiles are 0.003 except for $x=0.3 \mathrm{~m}$. On the other hand BRADLEY has determined $z_{01}=0.5 \mathrm{~cm}$ and $z_{02}=0.002 \mathrm{~cm}$, hence $z_{02} / z_{01}=0.008$. Comparisons between the velocity profiles predicted by the author and those predicted by the use of BRADLEY's $z_{01}$ and $z_{02}$ at each fetch are shown in Fig. 11-Fig: 13, where the velocity $u_{207}$ at $z=297 \mathrm{~cm}$ is chosen as the reference velocity.

It will be seen from these figures that there is no significant difference between our velocity profiles and those predicted by using BRADLEY's values of $z_{01}$ and $z_{02}$ at fetches of 5.5 and $13.9 \mathrm{~m}$, but the latter give slightly lower velocity at $x=27.0 \mathrm{~m}$. Also in this case, the tendency of the observed velocity profile to show higher velocity can not generally be found (although it seems that the velocity profile predicted by using BRADLEY's $z_{01}$ and $z_{02}$ gives slightly lower velocity at $x=27.0 \mathrm{~cm}$ ).

\section{Conclusion}

The results mentioned above may be summarized as follows:

1) The PANOFsKy-Townsend interface height $\delta^{\prime}$ is $e$ times the ElliotT interface height $\delta$.

2) The interface height $\delta$ (or $\delta^{\prime}$ ) is the function of both roughness parameters $\left(\begin{array}{ll}z_{01} & z_{02}\end{array}\right)$ and friction velocities $\left(v_{* 1}, v_{* 2}\right)$. But it may be represented empirically by the function of $x$ except for the region close to the transition.

3 ) The ratio of the shearing stresses on both surfaces (rough and smooth) $\tau_{0:} /$ $\tau_{01}$ is sensitive to the change of roughness.

4) The velocity profiles observed agree fairly well with those predicted by the PANOFSKY and TOWNSEND theory, and the acceleration reported by BRADLEY can not be found. 


\section{References}

BRADLEY, E. F., 1968: A micrometeorological study of velocity profiles and surface drag in the region modified by a change in surface roughness. Quart. J. Roy. Met. Soc., 94,361-379.

ELLIOTT, W. P., 1958: The growth of the atmospheric internal boundary layer. Trans. Amer. Geophys. Un., 39, 1048-1054.

KutZBACH, J.E., 1961 : Investigations of the modification of wind profiles by artificially controlled surface roughness. Univ. of Wisconsin, Dept. of Met. Annual Report. 71.

PAnofsky, H.A. and A.A. Townsend, 1964: Change of terrain roughness and the wind profile. Quart. J. Roy. Met. Soc., 90, 147-155.

STEARNS, C.R. and H. H. LETTAU. 1963: Two wind profils modification experiments in airflow over the ice of Lake Mendota. Univ. of Wisconsin, Dept. of Met. Annual Report. 115.

STEARNS, C. R., 1964: Wind-profile modification experiments using fields of Christmas trees on the ice of Lake Mendota. Univ. of Wisconsin. Dept. of Met. Annual Report. 59.

TAYLOR, R. J., 1962 : Small-scale advection and the neutral wind profile. J. Fluid Mech., 13, 529-539.

\section{地表面における内部境界層についての 2,3 の考察}

根本茂

BRADLEY (1968) によれば，粗い地表面から滑らかな地表面に急に変化する際，その境目からある程度離 れた風下側の各地点に怙触速の鉛直分布は PANOFSKY-TOWNSEND 理論によって推定された分布とあ まりよく一致しない。理論的淮定された風速の鉛直分布は実測された分布よりる風速の小さい方へずれ る，即ち実測された分布は加速されたような形になる。

しかし，その理由がよくかからないので，BRADLEY の観測值を用いてこの問題を再倹討してみた。

その結果，Roughness parameter を適切に選べば実測された風速の鉛直分布は PANOFSKY-TOWNSEND 理論によって推定された分布とよく一致し，BRADLEY のいらような加速は認められなかった。

(この研究は文部省科学研究費補助金に上る研究の一部である) 